Volume 7

Number 1 Spring 2016 (Special Issue)

Article 3

4-11-2016

\title{
From Bows to Sound-Chests: Tracing the Ancestry of the Violin
}

Janelle R. Finley

Cedarville University, janellefinley@cedarville.edu

Follow this and additional works at: https://digitalcommons.cedarville.edu/musicalofferings

Part of the Ethnomusicology Commons, Fine Arts Commons, Musicology Commons, Music Performance Commons, and the Music Theory Commons

DigitalCommons@Cedarville provides a publication platform for fully open access journals, which means that all articles are available on the Internet to all users immediately upon publication. However, the opinions and sentiments expressed by the authors of articles published in our journals do not necessarily indicate the endorsement or reflect the views of DigitalCommons@Cedarville, the Centennial Library, or Cedarville University and its employees. The authors are solely responsible for the content of their work. Please address questions to dc@cedarville.edu.

\section{Recommended Citation}

Finley, Janelle R. (2016) "From Bows to Sound-Chests: Tracing the Ancestry of the Violin," Musical Offerings: Vol. 7 : No. 1 , Article 3.

DOI: $10.15385 /$ jmo.2016.7.1.3

Available at: https://digitalcommons.cedarville.edu/musicalofferings/vol7/iss1/3 


\title{
From Bows to Sound-Chests: Tracing the Ancestry of the Violin
}

\section{Document Type}

Article

\begin{abstract}
The ancestry of the violin is a subject that has been studied, researched, debated, and written about in great detail. However, despite all of the research and study, the ancestry of the violin is still not certain. This paper presents two schools of thought that propose different theories as to how the ancestry of the violin should be determined and what instruments should be included in the ancestry of the violin. The first school of thought proposes that the violin's ancestry should be traced through the bow. The second theory proposes that the violin's ancestry should be traced through the sound-chest of the violin. This paper also presents the different arguments for and against each theory, the importance of this topic, and the paper's position on this topic. Research for this paper was accomplished through the use of scholarly books on the subject of the history of the violin.
\end{abstract}

\section{Keywords}

Violin, history, ancestry of the violin, theories of the history of the violin

\section{Creative Commons License}

\section{(c)}

This work is licensed under a Creative Commons Attribution-Noncommercial-No Derivative Works 4.0 License. 


\title{
From Bow to Sound-Chests: Tracing the Ancestry of the Violin
}

\author{
Janelle Finley \\ Cedarville University
}

$\mathrm{H}$ ave you ever wondered why we refer to the stringed instruments as a family? The violin (Figure 1) is part of the string family that consists of the violin, viola, cello, and bass. In addition to having a family, the violin has an extensive ancestry. Many people have researched the ancestry of the violin; however, only a few primary sources and pieces of solid evidence exist to help trace the ancestry of the violin. As a result, the ancestry of the violin is not certain and several theories have attempted to suggest the true ancestry of the violin. This paper will present three theories with arguments for and against each one.
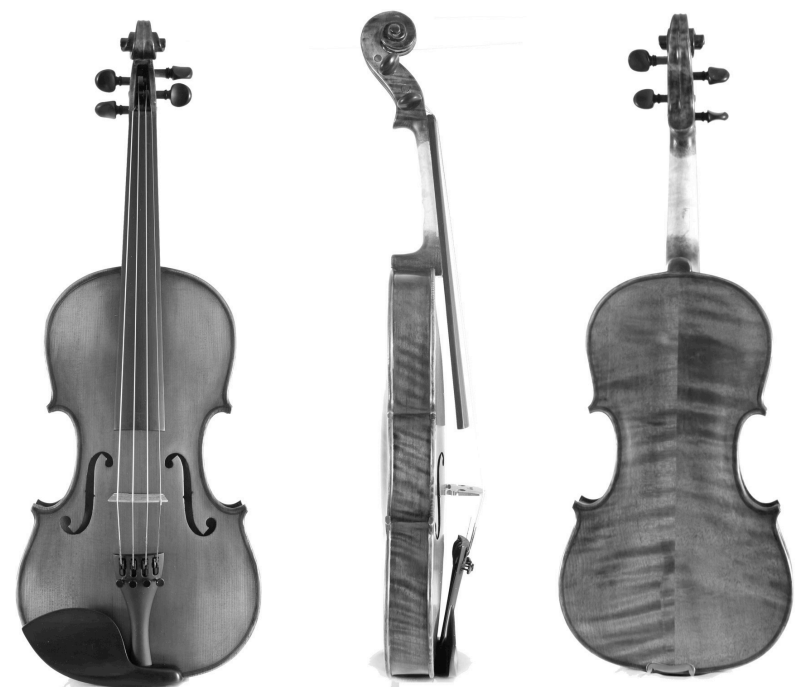

Figure 1: Violin. Lukas Carmen. http://univiolin.com/wpcontent/uploads/2013/04/Lukas-Carmen-Violin-1.jpg.

Musical Offerings, vol. 7, no. 1, pp. 27-42.

ISSN 2330-8206 (print); ISSN 2167-3799 (online);

(C) 2016, Janelle Finley, licensed under CC BY-NC-ND

(http://creativecommons.org/licenses/by-nc-nd/3.0/) 
The first school of thought traces the ancestry of the violin through the stringed instruments that are strictly accompanied by a bow. This theory claims that the bow produces the violin's unique tone. Without the bow, producing this tone would be impossible. Therefore, this theory asserts that the bow is of high importance and is the most crucial criterion in tracing the ancestors of the violin. ${ }^{1}$ Herron-Allen is an advocate for this theory and feels very strongly about it. He writes, "It has been justly remarked that the history of the violin is in point of fact the history of the bow, and this is indeed the case for without the bow the fiddle cannot exist." ${ }^{2}$ This theory proposes that the first ancestor of the violin is the Ravanastron (Figure 2), followed by the rebab, the rebec, and finally the viol, which led to the violin. All of these instruments are considered to be stringed instruments accompanied by a bow.

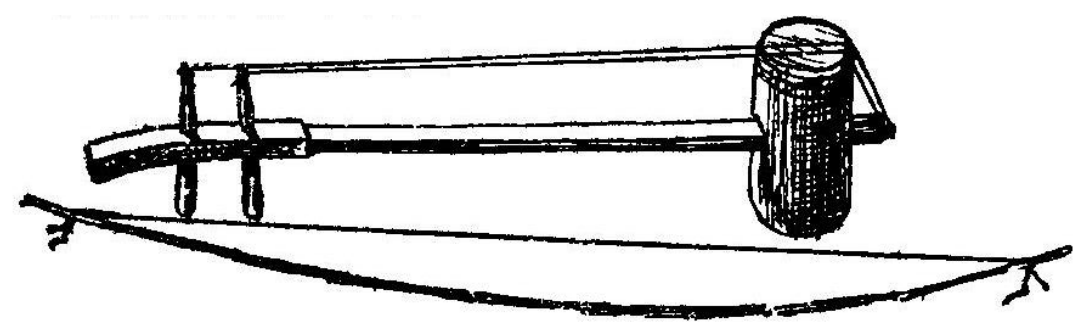

Figure 1: Ravanastron.

https://upload.wikimedia.org/wikipedia/commons/a/aa/Ravanastron ill ustration.jpg.

The Ravanastron (Figure 2) is chosen to be the first ancestor in this theory because it has the simplest structural form of all the bowinstruments traced throughout history. According to Sonnerat, Ravana who was the King of Ceylon at the time invented the Ravanastron. Hence the word "Ravanastron" is capitalized since it was named after Ravana. The Ravanastron was primarily found to be in use among the lower orders of people in isolated and mountainous districts. Its structure consists of a cylindrical piece of sycamore wood that is hollowed out from one end to the other, having the appearance of a tin can. Punctured through this cylindrical piece is a wooden neck. At one end of the neck is the cylindrical wooden piece and at the other end are two pegs, to which two strings are wound to and attached at the

\footnotetext{
${ }^{1}$ Yehudi Menuhin, and William Primrose, Violin and Viola (New York:

${ }^{2}$ Edward Heron-Allen, Violin-Making A Historical and Practical Guide (Mineola, NY: Dover Publications, 2005), 29.
} 
opposite end on the other side of the cylindrical piece. ${ }^{3}$ The structural features that the Ravanastron body has in common with the violin are the wooden pegs and the concept of the strings. The bow that accompanies the Ravanastron has a very rough form as well. It consists of a cane, possibly even without any hair attached to it. ${ }^{4}$ Other than these two body features and the bow, the Ravanastron is quite different from the violin. However, since this was the simplest form of the bowinstruments, it is considered to be the first ancestor of the violin.

The rebab (or rabab) is the second bow-instrument in the ancestral line. There are two main types of rebabs. The first (Figure 4) has the structural body of a pear-shaped lute with a short neck. The second type (Figure 3) has a long neck with a circular body, quadrangular body, or a bowl body made out of carved wood, gourd, or coconut shell. Once again the body of this instrument does not have much in common with the violin. However, according to this theory, the rebab contributed the structural feature of the short neck and open string tuning to the violin. ${ }^{5}$

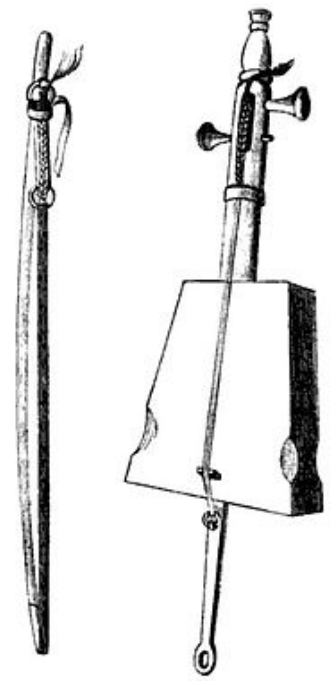

Figure 2: Rebab.

https://upload.wikimedia.org/wikipedia/commons/b/b1/F\%C3\%A9tis_r ebab_002.jpg.

\footnotetext{
${ }^{3}$ Ibid., 37-39.

${ }^{4}$ Ibid., 38.

${ }^{5}$ Jo Ann Hoffman, The Structural Evolution of the Violin to 1550 A.D.

(Dayton, OH: Wright State University Publishing Service, 1986), 97.
} 


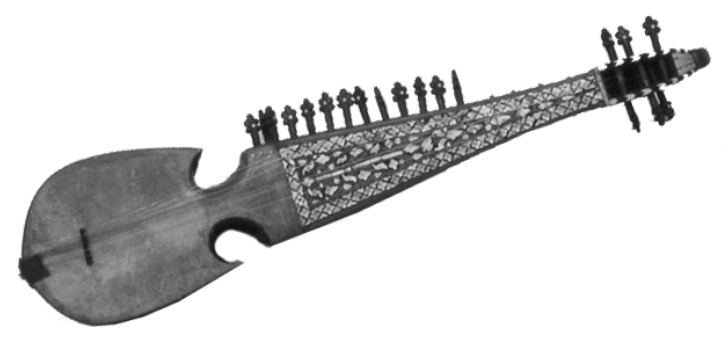

Figure 3: Rebab.

http://www.calmusical.com/price cat/Cat/2900 A.png.

According to this same theory, the next instrument in the ancestral line is the rebec (Figure 5). The rebec is also referred to as the ribible, rebelle, or rubebe. ${ }^{6}$ According to Hoffman, the rebec was a result of combining the structural elements of both the rebab and lira. Its body was that of the lira, except for the fact that the wood of the body was thinner than the lira, especially the soundboard on top. It was also carved into a more slender outline, which resembled the rebab. It had the raised neck of the lira, three or more strings that were tuned in perfect fifths, a pegbox with lateral pegs, accompanied with a short arched bow.

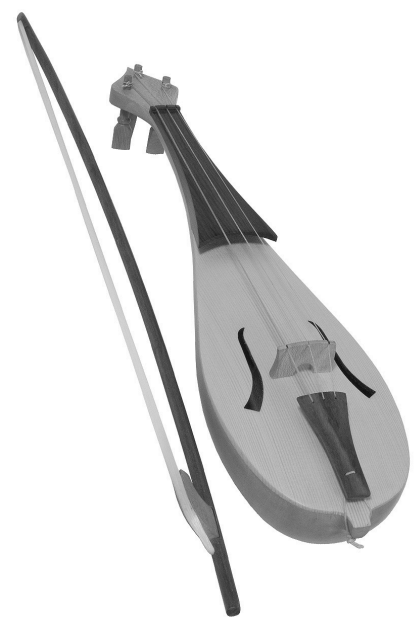

Figure 4: Rebec. http://www.mid-east.com/rebr.jpg.

\footnotetext{
${ }^{6}$ William Sandys and Simon Andrew Forster, History of the Violin (Mineola, NY: Dover Publications, 2006), 43.
} 
In illustrations, it is sometimes drawn with frets, but sometimes without frets. The structural features that contributed to the modern violin were the arched bridge, the sickle shaped pegbox, the first primitive scroll, lateral pegs, the lack of frets, the overhand bow hold, and its three strings tuned to the exact pitches of the modern violin. Before the rebec, all bridges were flat, but the rebec was the first instrument to introduce the arched bridge. ${ }^{7}$ According to Hoffman, "the scroll was used almost exclusively on instruments of the violin family. Since the weight of the scroll or head affects both the power and timbre of an instrument, it is not purely an ornamental feature." ${ }^{8}$ Therefore, the scroll truly contributed to the tone of the violin.

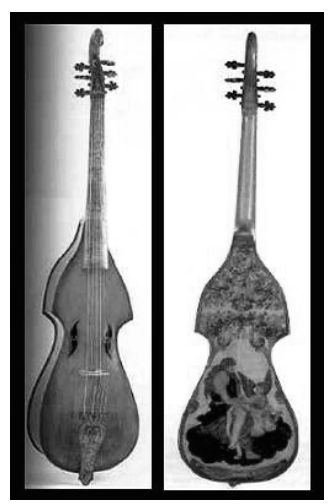

Figure 5: Pear-shaped viol.

http://www.thecipher.com/viol longthin_16th_survivor.jpg.

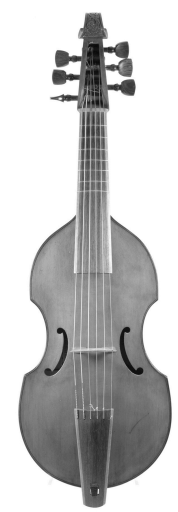

Figure 6: Viol with curvatures.

http://www.corilon.com/shop userdata/1/items/347 1 11.jpg.

\footnotetext{
${ }^{7}$ Hoffman, 205, 224.

${ }^{8}$ Ibid., 224.
} 


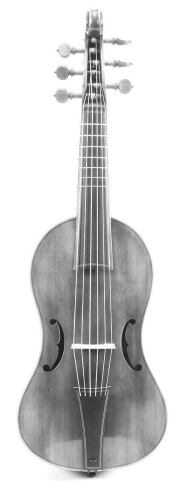

Figure 7: Oval-shaped viol.

http://www.devinhoughviolins.com/gallery\%20images /treble\%20viol/treble\%20viol front.jpg.

According to the bow theory, the viol is the last instrument in the ancestral line before the violin. According to Sandys and Forster, the viol was an instrument that went through a considerable amount of structural development. The oldest form of the viol had a pear-shape structure (Figure 6) that morphed into a more oval shape (Figure 8). Later, inward curvatures (Figure 7) were added in the middle of the body to make bowing easier. Throughout several centuries, the viol became very similar to the violin in form, except that the viol was of heavier make and had frets to guide the fingers. ${ }^{9}$

It is interesting to note that the second theory, the "sound-chest theory," completely disregards the viol to be in the ancestry of the violin. Straeten writes, "It must be clearly understood that the viols were not the parents of the violin family, but they were cousins who came into existence about the same time, both being descendants of the guitarfiddle" ${ }^{10}$ The second theory views the ancestry of the violin quite differently. It not only rejects the viol to be a part of the ancestry of the violin, but other instruments as well.

The second theory takes a drastically different approach to the ancestry of the violin in comparison with the first theory. Whereas the first theory laid its foundation for tracing the ancestry of the violin solely on

\footnotetext{
${ }^{9}$ Sandys, 50 .

${ }^{10}$ Edmund van der Straeten, The History of the Violin: Its Ancestors and Collateral Instruments from Earliest Times to the Present Day, (New York: DaCapo Press, 1968), 27.
} 
the history of the bow, the second theory asserts that the bow should not be taken into consideration at all. This theory argues that the structure of the violin itself is more important than the bow. The characteristic that sets the violin apart from any other bowed instruments is its tone. This special tone was not produced through the creation of the bow, but rather through the structural features of the violin's body (sound-chest). The structural features of the sound-chest are a back, and a soundboard either flat or delicately arched (these are the two larger pieces that are parallel to each other), joined by the sides or ribs of equal width, and sound holes placed on each side of the strings. ${ }^{11}$ Therefore, this theory, which will be referred to as the "sound-chest theory," includes instruments in the ancestry of the violin that possess structural characteristics of the violin's sound-chest.

There are several instruments that do possess this particular soundchest and are included in the ancestry of the violin. The ancestral line starts with the Greek cithera, followed by the Roman cithara, then the rotta (which was the Roman cithara in its transition stage), followed by the guitar fiddle, and finally to the Italian violin itself. Most genealogical tables of the violin actually start the genealogy with the Egyptian kithera as the first ancestor, followed by the Assyrian chetarah or ketharah, and then followed by the Greek cithera. Even though the Egyptian kithera is technically the first ancestor in the genealogical table, the Greek cithera takes importance and precedence over the Egyptian kithera. It is considered to be the first ancestor because Greece is where the cithera reached its greatest development. ${ }^{12}$

Looking at the Greek cithera (Figure 9), it appears to have nothing in common with the violin. However, its sound-chest is one that consists of a back and soundboard connected by sides (or ribs) of equal width, which are structural features of the violin. ${ }^{13}$

\footnotetext{
${ }^{11}$ Kathleen Schlesinger, The Precursors of the Violin Family: Records, Researches \& Studies (London: William Reeves, 1914), vi.

${ }^{12}$ Ibid., 70 .

${ }^{13}$ Ibid., 76.
} 


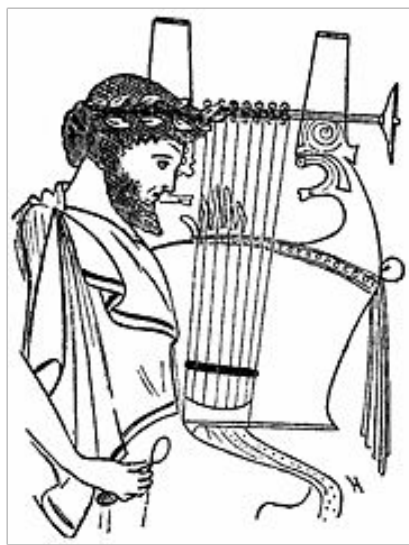

Figure 8: Greek cithera.

http://www.phy.duke.edu/ dtl/89S/restrict/Greece files/image010.png.

The general shape consists of a square base, with two arms that go up on each side, and a crossbar (yoke) that rests on top of the two arms, to which the strings are attached. As mentioned before, the Greek cithera went through many stages of development.

According to Hoffman, the earliest known form of the Greek cithera dates back to the eighth century B.C. The corners of its base were rounded off (Figure 10), rather than square and only had three to four strings. The strings were attached to the crossbar with thongs of greased hide rather than tuning rods. The back of the cithera actually had the same structural feature as the violin, arching a little in the middle of the backboard rather than being flat.

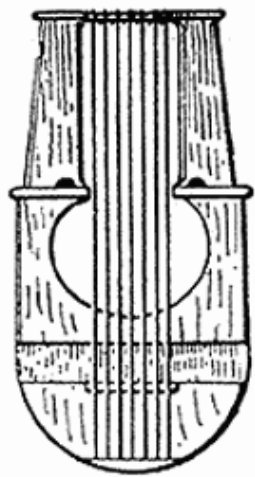

Figure 9: Early Greek cithera.

http://levigilant.com/Bulfinch Mythology/bulfinch.englishatheist.org/b/ pantheon/images/CitharaSketch.gif. 
During the seventh century B.C., the number of strings increased to a set of seven. The base also took on square corners rather than rounded corners. The cithera of the seventh century not only developed some structural features, but also added several new features as well that are reflected in the violin today. These structural features included the tailpiece and bridge. The tailpiece was a box tailpiece rather than a flat, curved tailpiece that the violin bears. The bridge was a low bridge rather than being a high bridge as well. Even though these features slightly differ from those of the violin, they still incorporate the same ideas and concepts that the violin does.

During the fifth century B.C., the demand for more technical skill and musical virtuosity had increased. As a result, more strings were added to the cithera, totaling up to twelve strings, to increase the range and possibilities of notation. Guitars and lutes at this time had necks that made the task of producing many notes and chromaticism very possible. A neck could have easily been added to the cithera, but the Greeks did not accept necked instruments because necked instruments were of low status in the eyes of the Greeks. Hoffman asserts that the body of the violin could have been easily developed at this point in history, but because of the Greeks' view of necked instruments, they continued to alter the neckless cithera to meet their needs. In the fifth century B.C. sound holes were added to the cithera. Although the sound holes were circular, differentiating from the sound holes of the modern violin, the idea of the sound hole remained fundamental in instruments leading up to the violin. Even though the cithera did not develop into the violin, it still contributed the structural features of the back, the tailpiece, the bridge, and the presence of the sound holes. Just as the violin was considered to be an instrument of the professional and elite world, so was the Greek cithera. The cithera was greatly respected in Greek society. Because of all of its developments, it was an elaborate instrument that was favored by professionals rather than the just the common people. ${ }^{14}$

The next string instrument in the lineage of the violin according to the sound-chest theory is the Roman cithera. The Roman cithera is very similar to the Greek cithera, considering that the Roman cithera is the Greek cithera, with a few structural changes. It was simply called a "Roman" cithera because of its location in Rome. The Romans were more attracted to the loud and powerful tones of the wind instruments

${ }^{14}$ Hoffman, 77-80. 
rather than the soft and gentle tones of the string instruments. As a result, their focus was on the wind instruments and they were content with the Greek style and development of the cithera. However, the Roman cithera did have the structural feature advancement of the tuning rods, which is a structural feature found in the violin. As Hoffman states, "While the violin does not use tuning rods per se, a rod inserted into the wood instead of next to it was the first mobile tuning peg." 15

Following after the Greek and Roman cithera is the rotta (Figure 11). "Rotta" was the name that was designated to the Roman cithera in its transition stage during the Middle Ages. Its name is written and mentioned in many different ways, such as rotte, hrotta, hrota, rotteh, rote, and riote. ${ }^{16}$ There is minimal solid evidence for the existence of the rotta, or even for the fact that it was a transition instrument. Schlesinger mentions that there is little evidence to guide one through this particular transition period of the rotta besides some allusions in the writings of the fathers, some coins, and miniatures in MMS. ${ }^{17}$ However, based off of these sources, this theory has concluded that the rotta developed several key structural features of the violin.

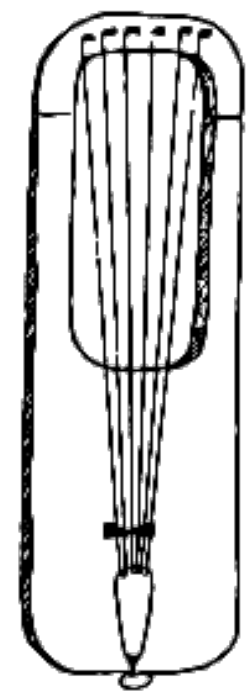

Figure 10: Rotta. http://www.housebarra.com/EP/ep03/ep03 004.gif.

\footnotetext{
15 Ibid., 85.

${ }^{16}$ Carl Engel, Researches into the Early History of the Violin Family (Amsterdam: Antiqua, 1965), 48.

${ }^{17}$ Schlesinger, 113.
} 
The first feature was that the arms were removed from the sound-chest and the sound-chest took on a rectangular body shape rather than a square one. ${ }^{18}$ It was constructed in such a way that the whole length of the strings would lie over the resonant body, rather than just part of the sound-chest. ${ }^{19}$ The second feature was a neck and a fingerboard attached to the sound-chest that in some cases was fretted with three to four strings. The rotta was very close to the structure of the violin, however it was still plucked, and didn't have the use of a bow.

The guitar-fiddle (Figure 12), according to this theory is the instrument that came after the rotta, and paved the path for the creation of the viol and violin. The guitar-fiddle possesses a grand history itself in light of the fact that it was in development from the time of Ancient Egypt, to the time of the Middle Ages. As a result, the guitar-fiddle took on different forms and structural features in various countries throughout the centuries. There was the Egyptian fiddle-guitar (Figure 13) that had an extremely long neck, the German fiddle-guitar with a shorter neck and arched bridge, the Spanish guitar-fiddle, and the guitar-fiddle from England and Italy.

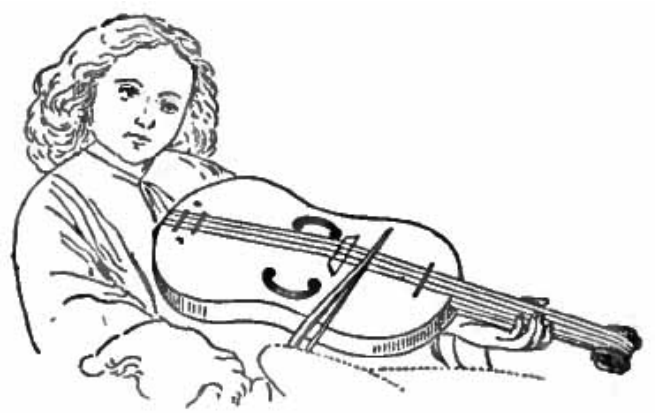

Figure 11: Guitar-fiddle.

https://upload.wikimedia.org/wikipedia/commons/9/96/Britannica Guit ar_Fiddle_Typical_Alto.jpg.

\footnotetext{
${ }^{18}$ Ibid., 223.

${ }^{19}$ Ibid., 114.
} 


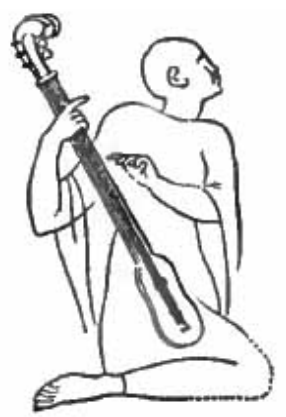

Figure 12: Egyptian guitar-fiddle.

https://upload.wikimedia.org/wikipedia/commons/3/39/Britannica_Guit ar Egypt.jpg.

However, throughout all of the centuries and different structural transitions of the guitar-fiddle, there were a few structural characteristics that remained foundational. Schlesinger describes the foundational structural features of the guitar-fiddle in the following: "The shape of the sound-chest (shallow, with ribs); incurvations like those of the modern guitar, without corner blocks; a fingerboard, and a separate neck added to the body." ${ }^{20}$ Many of these features already existed in previous instruments except for the incurvations, which was the new structural feature that contributed to the modern violin. This concludes the stringed instruments in the line of the violin according to the sound-chest theory.

So far, two theories concerning the ancestry of the violin have been presented, each being quite different from the other. Advocates for each of these theories have very strong arguments for the theory they support, but they also have very strong arguments against the opposing theory as well. The arguments for the bow theory and against the sound-chest theory will be presented first.

Most importantly, the bow theory argues that without the bow, the violin could not exist and it would not be able to produce its unique tone. Menuhin states, "the distinguishing feature and crowning beauty of its [the bow's] tonal capabilities has always resided - and will doubtless so continue to reside - in its unmatched cantilena, made possible only by the skillful wielding of the bow." ${ }^{21}$ Heron-Allen states that without the bow, the violin would "cease to express every human

\footnotetext{
${ }^{20}$ Ibid., 229.

${ }^{21}$ Menuhin, 194.
} 
emotion," would "cease to produce the continuous flow of melody," and would "become as the sounding guitar and tinkling banjo." $22 \mathrm{He}$ also mentions that it is only because of the bow that instruments of the violin family are capable of producing a continuous flow of melody and human-like imitations. ${ }^{23}$

A second argument for the bow theory would be the craftsmanship of Andreas Amati. Amati is widely known to be one of the first violinmakers. However, Amati was originally a maker of viols and rebecs and did not start making violins until later on in his career. ${ }^{24}$ The fact that he was first a maker of rebecs and viols and later a maker of violins, fits the bow theory perfectly. As mentioned before, the two instruments that preceded the violin in the bow theory were the rebec and viol.

A third argument or defense could be made for the validity of the bow theory including the rebab and rebec and other pear or club-shaped (long necks, with small circular or square bodies at one end) instruments in the ancestry of the violin. An argument could be made that instruments that had the characteristics of the rebab and rebec were popular in Europe. According to Hoffman, "Western Europeans preferred the slender, club-shaped instruments." 25

Concerning the beliefs and arguments of the sound-chest theory, they are almost the complete opposite of the bow theory. First and foremost the sound-chest theory believes that the bow should not be taken into consideration at all. The sound-chest theory believes that the unique tone of the violin comes from the structural features of the sound-chest rather than the bow. This theory argues that there have been other stringed instruments accompanied by a bow throughout history, but none of them have ever been able to attain or exceed the tone quality of the violin simply because they do not possess the unique sound-chest of the violin. The sound-chest theory asserts that the structure of the body, or the sound-chest is more important than the bow, and therefore should be the means to tracing the ancestry of the violin.

\footnotetext{
${ }^{22}$ Heron-Allen, 86.

${ }^{23}$ Ibid.

${ }^{24}$ Ibid., 73.

${ }^{25}$ Hoffman, 196.
} 
The bow theory responds to this particular train of thought with strong disagreement. The bow theory believes that certain sound-chest instruments, such as the cithera, should not be included in the ancestry of the violin at all. Menuhin says, "The shape, construction, and technique of the kithara differ so much from the various attributes of the violin that any attempt to relate the two instruments must be classed with the kind of pseudo-philology which derives the word virgin from vir (Latin) and gin (Old English) with the resulting connotation of mantrap. ${ }^{, 26}$ The sound-chest theory would respond by saying that it is the sound-chest components (a back, and a soundboard either flat or delicately arched, joined by sides or ribs of equal width, and sound holes placed on each side of the strings) that are truly important, not the technique as to how it was played, or if it was accompanied by a bow or not.

Another strong argument for the sound-chest theory is the fact that the violin and its ancestors that are included in the sound-chest theory's particular lineage have all been considered to be instruments of prestige. As mentioned before, the Greek cithera was used by professional players and was considered to be an instrument of prestige like the violin. The stringed instruments in the bow theory's lineage, however, are not considered to be instruments of prestige. Hoffman specifically mentions that the Rebab was used among the lower classes. ${ }^{27}$

The last argument the sound-chest theory presents against the bowtheory is the absurdness of including the viol in the ancestry of the violin. The sound-chest theory asserts that the viol should not be included in the ancestry of the violin at all. Hoffman states, "contrary to modern misconception, most organologists (including Straeten and Sachs) agree that the viols and violins were two totally separate branches of the evolutionary tree; one never led to the development of the other." ${ }^{28}$ Straeten also argues that the early viol form evolved from the guitar-fiddle. ${ }^{29}$ The violin evolved from the guitar-fiddle as well. Therefore, Straeten argues that the viol was not the father of the violin, but was rather a cousin who came into existence around the same time. $^{30}$

\footnotetext{
${ }^{26}$ Menuhin, 193-4.

27 Jo Ann Hoffman, 96.

${ }^{28}$ Ibid., 225.

${ }^{29}$ Van der Straeten, 25.

${ }^{30}$ Ibid., 27.
} 
These two theories make their own valid points and solid arguments for the "correct" ancestral line of the violin. However, I am not convinced that either of these two theories proposed the correct lineage of the violin or the correct criteria to trace the ancestry of the violin. Through much reading and research, I have come to the conclusion that there is yet another theory, one that is a convergence of the bow and soundchest theory. I propose that different components of various bowed and stringed instruments preceding the sixteenth century were combined to produce the violin. Throughout my research I became convinced that one cannot trace the ancestry of the violin solely through bowed instruments or solely through sound-chest instruments, but rather, one should trace the ancestry through instruments that possess both of these characteristics. Both the bow and the sound-chest were instrumental in the creation of the violin.

Moving forward, three theories have been presented. As you side with a particular theory, you also side with a particular lineage of the violin as well. All three theories present lineages that are drastically different. Just as you would want to trace your own family's ancestry correctly, it is important to trace the ancestry of the violin correctly as well. It is important to know what makes the violin the violin. Knowing the true ancestors of the violin will give credit to whom credit is due and increase one's appreciation for the instruments that had an impact on its birth. 


\section{Bibliography}

Engel, Carl. Researches Into the Early History of the Violin Family. Amsterdam: Antiqua, 1965.

Heron-Allen, Edward. Violin-Making: A Historical and Practical

Guide. Mineola, NY: Dover Publications, 2005.

Hoffman, Jo Ann. The Structural Evolution of the Violin to 1550 A.D.

Dayton, OH: Wright State University Publishing Service, 1986.

Menuhin, Yehudi, and William Primrose. Violin and Viola. New York:

Schirmer Books, 1976.

Sandys, William, and Simon Andrew Forster. History of the Violin.

Mineola, NY: Dover Publications, 2006.

Schlesinger, Kathleen. The Precursors of the Violin Family Records,

Researches, \& Studies. London: William Reeves, 1914.

Van der Straeten, Edmund. The History of the Violin: Its Ancestors and

Collateral Instruments from Earliest Times to the Present Day.

New York: DaCapo Press, 1968. 